\title{
BIBECHANA
}

A Multidisciplinary Journal of Science, Technology and Mathematics ISSN 2091-0762 (Print), 2382-5340 (Online)

Journal homepage: http://nepjol.info/index.php/BIBECHANA

Publisher: Research Council of Science and Technology, Biratnagar, Nepal

\section{Chaupadi during menstruation still a major community health challenge: perspective from Mid-Western Nepal}

\author{
S. B. Parajuli ${ }^{1 *, 2}$, Heera KC ${ }^{3}$, A. Mishra ${ }^{1}$, P. Bhattarai ${ }^{4}$, M. Shrestha ${ }^{5}$, K. Srivastav ${ }^{6}$ \\ ${ }^{1}$ Department of Community Medicine, Kathmandu University-Birat Medical College \& Teaching \\ Hospital, Tankisinuwari, Nepal \\ ${ }^{2}$ Nepal Medical Volunteer Society, Biratnagar, Nepal \\ ${ }^{3}$ Department of Nursing, Purbanchal University-Birat Health College, Biratnagar, Nepal \\ ${ }^{4}$ Department of Physiology, Kathmandu University-Birat Medical College \& Teaching Hospital, \\ Tankisinuwari, Morang, Nepal \\ ${ }^{5}$ Department of Community Health Nursing, Purbanchal University College of Medical and Allied \\ Health Sciences, Gothgaun, Nepal \\ ${ }^{6}$ MBBS Student, Kathmandu University-Birat Medical College \& Teaching Hospital, Tankisinuwari, \\ Nepal \\ "E-mail: drsathii@yahoo.com
}

Article history: Received 02October, 2018; Accepted 10 November, 2018

http://dx.doi.org/10.3126/bibechana.v16i0.21645

This work is licensed under the Creative Commons CC BY-NC License.

https://creativecommons.org/licenses/by-nc/4.0/

\section{c) (7) (8)}

\begin{abstract}
Introduction: Menstruation, a normal physiological process in reproductive life of female still has many misconceptions. Knowledge of menstrual hygiene and menstrual sanitation practices affects the health of female. Lack of awareness on menstrual care practice is a challenge for community health.

Objective: The objective of this study was to find knowledge and practice on menstrual hygiene; and perspective of Chaupadi (menstrual shed) among the reproductive age group female.

Methodology: A community based mixed method study having cross sectional study as quantitative domain and phenomenological study as qualitative domain was conducted in Maranthana community of Pyuthan district of mid-western Nepal from April 2016-September 2016. Using convenient sampling techniques, 109 participants were included for cross sectional study and five of them who experienced Chaupadi were enrolled for phenomenological study. One eligible participant form each household was taken after getting informed voluntary consent. Collected data was entered in Microsoft excel and analysed by SPSS and NVivo software.
\end{abstract}

Results: Regarding knowledge, $73.7 \%$ were aware on the right age of menarche. Almost $93 \%$ were aware on possible pregnancy after initiation of menstruation. Many of them (34.9\%) were informed on menstruation by friends. Almost half (45.9\%) had negative belief of use of old clean cloth during menstrual flow. Regarding practice, only $40.4 \%$ used sanitary pad during their menstrual flow. Most $(65.1 \%)$ of them did not dispose, $16.5 \%$ bury in nearby ground and $18.4 \%$ burn. More than half $(60.6 \%)$ used soap-water to clean genitalia. Remedial measures adopted during menstruation were taking adequate rest (44\%), seeking medical advice (22.9\%) and drinking plenty of fluid (13.8\%). Different traditional practice followed were use of separate utensils (64.2\%), not allowed to see sun (75.8\%), restriction to- go outside (71.6\%), cook food (56\%), usual food intake (56.9\%), worship (74.3\%), eat with others (27.5\%), sleep in usual bedroom (27.5\%) and touch male members $(28.4 \%)$. 
Most (94.5\%) of them experienced Chaupadi (Menstrual Shed) during their menarche. The phenomenological approach found that Chaupadi was common. They had various infections and ill health. Mother groups were advocating to eliminate Chaupadi in their locality.

Conclusion: The know-do gap on menstruation was evident. Despite increasing awareness, people were still following traditional cultural practices.

Keywords:Awareness; menstruation; reproductive age group; western Nepal.

\section{Introduction}

Menstruation is a periodic vaginal bleeding occurring every 26 to 30 days in women of childbearing age (15-49 years). It is a matter of both reproductive and environment health [1]. Onset of menstruation is a unique phenomenon for adolescent girls [2]. Nepali society still consider it as a matter of impurity, secrecy and ashamed of being disclosure of their menarche [1,3]. It is considered unclean, and young girls are restricted from participating in household and religious activities during menstruation. These restrictions extend to eating certain foods like Jaggery and papaya as well $[2,4]$. There is a strong traditional belief of staying in an unhygienic place (Chhaupadi) for several days, not allowing to see sun, not allowing to touch male members, books, restrictions of entering holy places and cultural taboos with foods, using unclean pads and improper disposal of used pads. ${ }^{(1)}$ It is a traditional practice in which females are forbidden to touch anything and are forced to live in isolation (shed) during menstruation [5].In some areas, women are expected to sleep outside in a tiny hut called a goth until they are clean again. This custom is called chaupadi, derived from two Hindu words: chau, meaning menstruation, and padi, meaning women [6]. Women often lacks knowledge regarding menstruation and good hygiene practices. Hence, are vulnerable to reproductive organs diseases[7]. Many adolescents girls are neither informed nor taught in school about menstruation as it is considered a subject not to be discussed [1,7]. A study found that female were not properly maintaining the menstrual hygiene [7]. The limited knowledge available was passed down informally from mothers, who were themselves lacking in knowledge of reproductive health and hygiene due to low literacy levels and socioeconomic status [8]. Lack of menstrual hygiene was found to result in adverse outcomes like reproductive tract infections [9]. Better knowledge about menstrual hygiene reduced this risk [4]. Knowledge regarding puberty change, source of menstrual blood and route of urine and menstrual flow was low. Moreover, water and sanitation at school, in workplaces and at home need to be addressed to reduce the need for unhygienic practices and reproductive tract infections. Around half of both urban and rural women experience negative impact of peri-menstrual changes. Rural women faced more challenges on dos and don'ts on certain activities while menstruating [10].The objective of this study was to find knowledge and practice on menstrual hygiene and perspective of Chaupadi (menstrual shed) among the reproductive age group females of Maranthana community of Pyuthan district, Nepal.

\section{Methodology}

A community based mixed method study having cross sectional study as quantitative and phenomenological study as qualitative domain was conducted at Maranthana community of Pyuthan district of mid-western Nepal from April 2016-September 2016. Sample size was calculated based on a research done at rural Nepal where prevalence of menstrual knowledge was found to be $83.3 \%$ [11].A convenient sampling technique was used to collect data from 109 households. Reproductive age (15 to 49 years) females from each household were selected for interview. Five participants who experienced Chaupadi were enrolled for phenomenological study. Data was collected by means of face-to-face interview using a semi-structured questionnaire. The pre-testing of the question done at Simariya Community of Sunsari district, Nepal. 
S.B. Parajuli et al. / BIBECHANA 16 (2019) 228-235: RCOST p.230 (Online Publication: Dec., 2018)

Informed consent was taken and confidentiality of each participants was maintained. The collected data was entered into Microsoft excel and analysed by SPSS and NVivo software.

\section{Results}

\section{Socio-demography}

In this study, 109 participants of reproductive age (15-49 years) group female were taken. The mean age of the participants was 24.82 with standard deviation of 8.12 years. Majority $(65.1 \%)$ of them were Brahmin/Chhetri by ethnicity and all of them were Hindu. Seven out of 10 had passed secondary level education and married. Sixty percent of them were housemaker and from nuclear family $(61.5 \%)$ having family size of 5.30. Average monthly family income was NRS. 20,000. About 62.4\% experienced menarche at the age of 13-14 years.

\section{Status of knowledge on menstruation}

Menstruation has many components. The different knowledge components on menstruation were depicted in table and figure.

Table 1 illustrates the different knowledge variable of menstruation such as $73.7 \%$ were aware on the right age of menarche, $67.9 \%$ were aware of menarche before their menstruation, $55 \%$ rightly reflect the definition of menstruation. Almost $93 \%$ were aware on possibility of pregnancy after initiation of menstruation. Many of them received information from friends (34.9\%) and their mother (33\%).

Table 1: Knowledge on different variables of menstruation $(\mathrm{n}=109)$.

\begin{tabular}{|l|c|}
\hline Variables & Yes (\%) \\
\hline Aware on right age of menarche & 73.7 \\
\hline Awareness on menarche before their menstruation & 67.9 \\
\hline Right definition of menstruation & 55.0 \\
\hline Possibility of pregnancy after initiation of menstruation & 93.0 \\
\hline Source of information on menarche & \\
Friend & 34.9 \\
Mother & 33.0 \\
Sister & 22.9 \\
Teacher & 0.9 \\
Books & 8.3 \\
\hline
\end{tabular}

Regarding knowledge on use of ideal things during menstruation, there was mixed response. The correct method, use of sanitary pad was known to $38.5 \%$ of the participants. About $45.9 \%$ said use of clean old clothes would be okay followed by any old cloth (11.9\%) (figure 1).

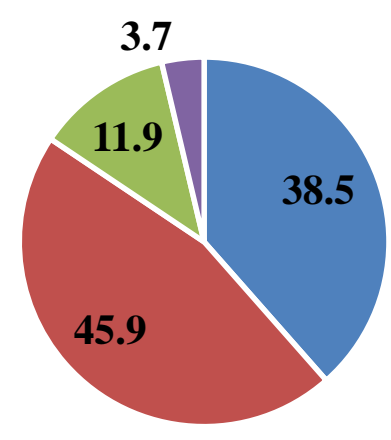

\section{Percentage}

- Sanitary pads

- Clean old clothes

- Any old clothes

- Others

Fig. 1: Ideal thing to be used during menstruation $(n=109)$. 
S.B. Parajuli et al. / BIBECHANA 16 (2019) 228-235: RCOST p.231 (Online Publication: Dec., 2018)

In table 2 , only $40.4 \%$ used sanitary pad during menstruation. Regarding disposal of sanitary pad, $65.1 \%$ do not dispose, $16.5 \%$ bury in nearby ground and $18.4 \%$ used to burn. Only $60.6 \%$ used to clean genitalia during menstruation with soap-water. Remedial measures adopted during menstruation were taking adequate rest (44\%), seeking medical advice if needed (22.9\%), and drinking plenty of fluid $(13.8 \%)$.

\section{Status of practice on menstruation}

Table 2: Modern practices followed on menstruation $(n=109)$.

\begin{tabular}{|l|c|}
\hline Variables & Yes (\%) \\
\hline Use of sanitary pad & 40.4 \\
\hline Disposal methods of sanitary Pad (n=44) & \\
Don't dispose & 65.1 \\
Bury in nearby ground & 16.5 \\
Open burning & 18.4 \\
\hline Clean genitalia & \\
Soap-water & 60.6 \\
Water & 39.4 \\
\hline Remedial measures adopted during menstruation & \\
Taking rest & 44.0 \\
Seeking medical advice & 22.9 \\
Drinking plenty of fluid & 13.8 \\
None & 19.3 \\
\hline
\end{tabular}

As in figure 2, different traditional practice adopted were use of separate utensils (64.2\%), not allowed to see sun (75.8\%), no permission to go outside (71.6\%), no permission to cook food (56\%), restriction of usual food (56.9\%), banned for worshiping god (74.3\%), used to eat in separate place (27.5\%), not allowed to sleep in usual bedroom (27.5\%) and restrict to touch male members $(28.4 \%)$. Most (94.5\%) of them experienced Chaupadi (Menstrual Shed) during their menarche.

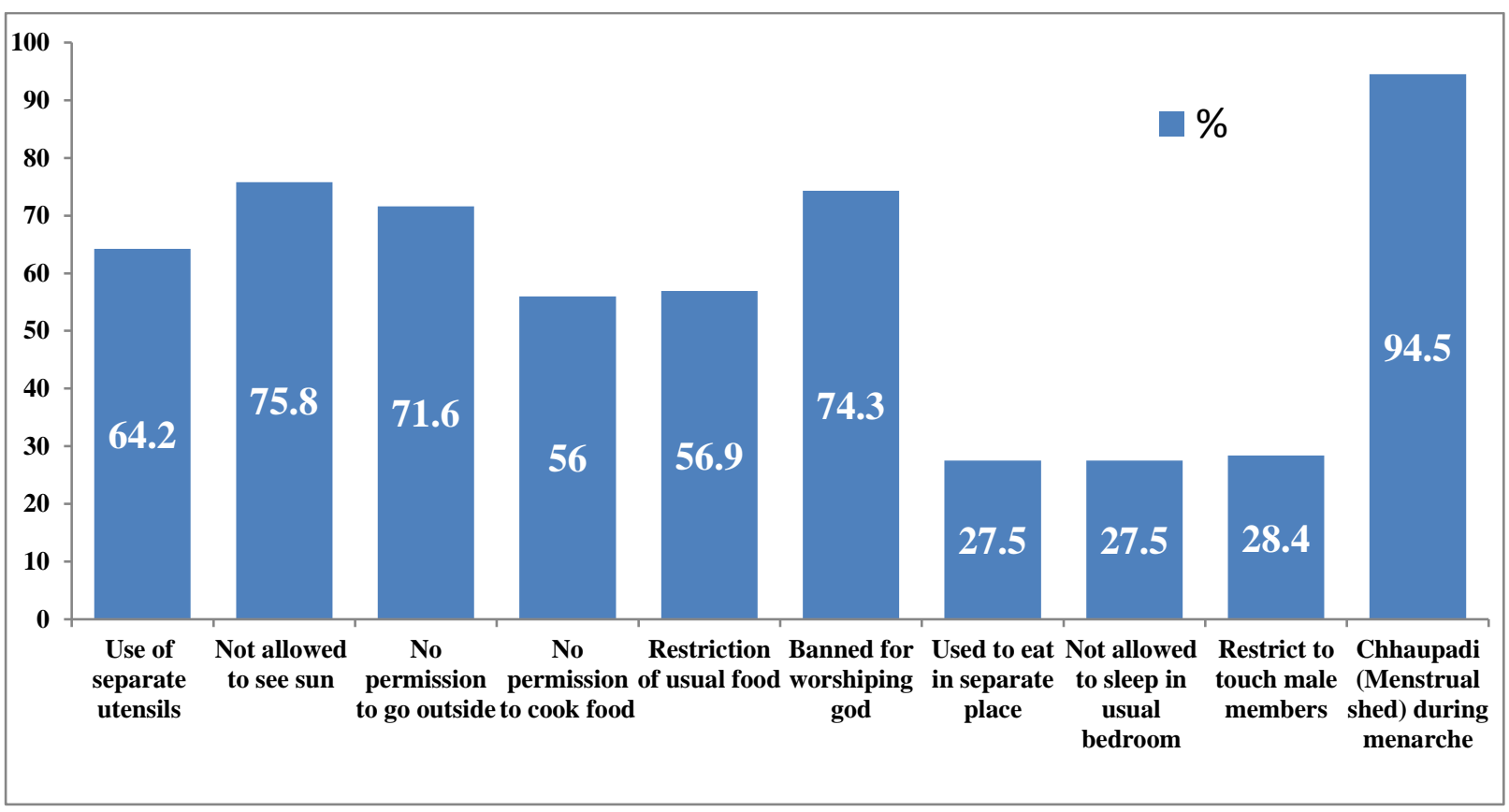

Fig. 2: Traditional practices during menstruation $(n=109)$. 
S.B. Parajuli et al. / BIBECHANA 16 (2019) 228-235: RCOST p.232 (Online Publication: Dec., 2018)

Chaupadi, a worse practice during menstruation was common during menarche. The five participants who had experienced Chaupadi were selected for phenomenological study. The mean age of the participant was 27 year and all were literate. All participants had awareness on possible health consequences of Chaupadi. Four out of five were against the Chaupadi practice but one said that this is very difficult to quit this practice today because it has become a part of their culture. They reflected that after few generations, it will automatically vanish. Snake bite, animal bite, mental problems, social deprivation, ill health, depression were commonly found health problems during Chaupadi. Many organisation were working for reproductive health issues in their area but still the wrong practices were prevailed. Comparing to past years, the practice of Chaupadi was decreasing day by day. More awareness, social inclusion, advocacy are the common factors for decreasing trend of Chaupadi. To stop the practice of Chaupadi, there was need for more advocacy at individual, family and community level. Different mother groups were advocating eliminating Chaupadi in their locality. Figure 3 depicts the illustration showing Chaupadi practice in med-western Nepal. Different traditional social taboos are reflected through the illustration.

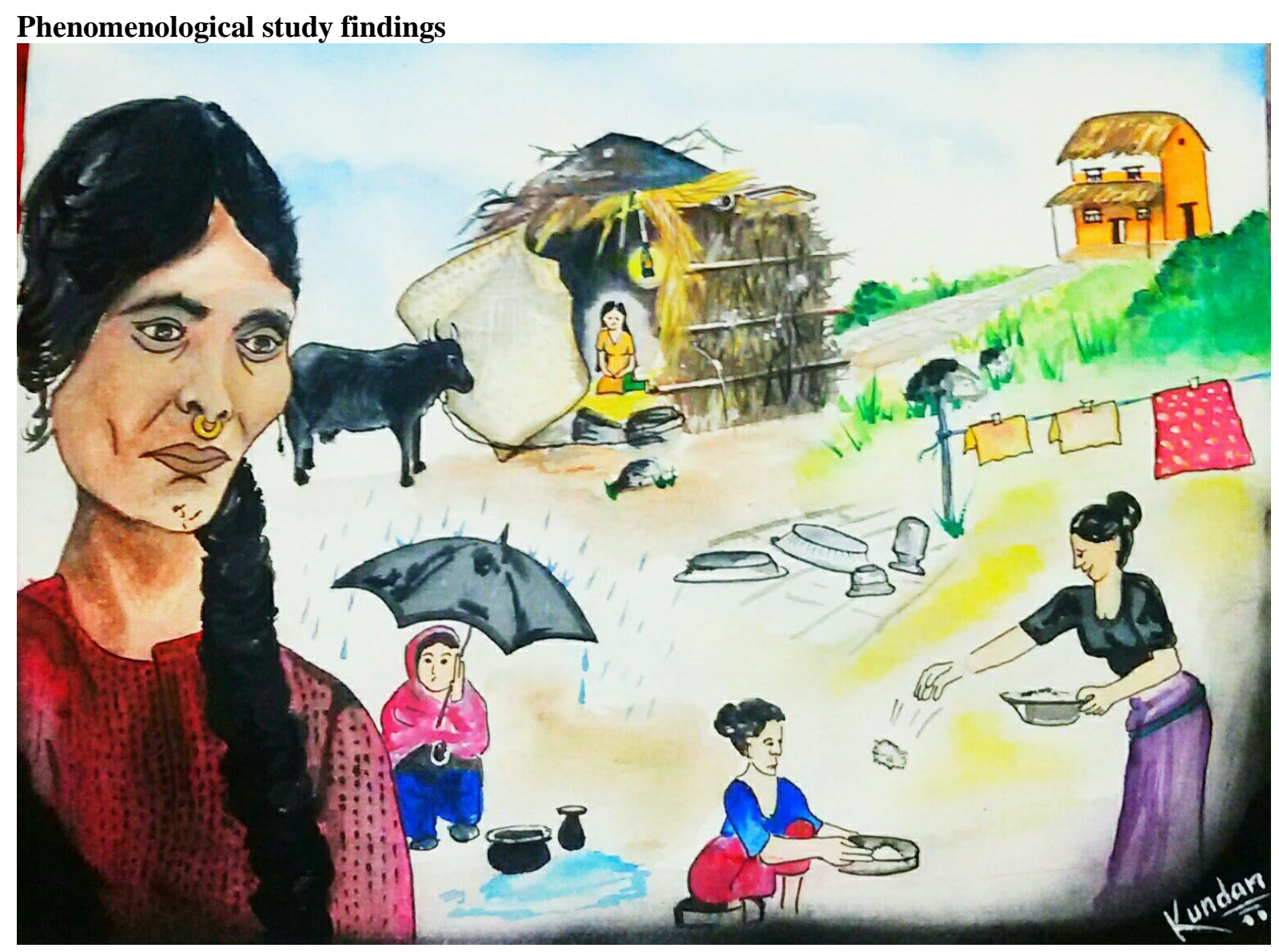

Fig. 3: Illustration showing Chaupadi System in Mid-western Nepal.

\section{Discussion}

The mean age of the participants was 24.82 years and majority (65.1\%) of them were Brahmin/Chhetri by ethnicity and all of them were Hindu. Seven out of 10 had passed secondary level education and married. Majority $(60 \%)$ of them were housemaker and from nuclear family $(61.5 \%)$. This study found that $62.4 \%$ experienced menarche at the age of 13-14 years. 
S.B. Parajuli et al. / BIBECHANA 16 (2019) 228-235: RCOST p.233 (Online Publication: Dec., 2018)

Similar result were found in another study where the mean age at menarche was found to be 13.1 year [3] and13.28 years [12]. In a study from Saudi Arebia, the mean menarcheal age was quite low (12.08 year) [13]. In the present study, 73.7\% were aware on the right age of menarche, $67.9 \%$ were aware of menarche before their menstruation. Almost similar result found in a study where $67.2 \%$ knew about menstruation before menarche [3].This study found that, 55\% rightly reflect the definition of menstruation. It was more in a study from eastern Nepal where $83.3 \%$ of girls knew that menstruation is a physiological process [11]. Another study found that $36 \%$ were aware on definition of menstruation [3]. Similarly, another study reported that participants were aware on menstruation as a physiological process (83\%) [14]. Every nine on ten were aware on possible pregnancy after initiation of menstruation in this study. More than one third of the participants (34.9\%) were informed by friends followed by mother (33\%) in the present study while in a study from eastern Nepal $53.9 \%$ participants were taught about menstruation by their mother [11]. In another study, most common informant was mother (39.3\%) [3]. Mothers were the first informant to 56\% girls [12]. This study found that $45.9 \%$ had negative belief of use of old clean cloth during menstrual flow. This study found that, $40.4 \%$ used sanitary pad during their menstrual flow. Another research from eastern Nepal reported only $33.3 \%$ of the respondents used sanitary pad during menstruation [11]. In this study, most $(65.1 \%)$ of them did not dispose, $16.5 \%$ bury in nearby ground and $18.4 \%$ used to burn the sanitary pad. Another study found that $29.5 \%$ burn, $27.9 \%$ dispose in pit or throw somewhere [3]. Inanother study it was found that $75 \%$ wrap in paper/polythene bag and dispose [12]. In this study, $60.6 \%$ used to clean genitalia during menstruation with soap-water where as in another study $66.54 \%$ girls were using water to clean genitals during menstruation [15]. Remedial measures adopted during menstruation were taking adequate rest (44\%), seeking medical advice if needed (22.9\%), and drinking plenty of fluid (13.8\%) in the present study. This study found that different traditional practice followed were use of separate utensils (64.2\%), not allowed to see sun (75.8\%), no permission to go outside (71.6\%), no permission to cook food (56\%), restriction of usual food (56.9\%), banned for worshiping god (74.3\%), used to eat in separate place $(27.5 \%)$, not allowed to sleep in usual bedroom (27.5\%) and restrict to touch male members $(28.4 \%)$. Different studies from different places found that $55.7 \%$ not allowed to cook/touch utensils[3], 43\% not allowed to enter kitchen[12], 91.6\% restricted from attending religious functions[3], 70\% not allowed to enter temple or participate in religious activities [3,12]. About $20 \%$ were not allowed to touch/sit/talk with male member of family[3], 55.7\% not allowed to do household chores, $16.4 \%$ forced to go away from home or in corner of room[3], 58.4\% not allowed to cook and visit temples [7].

This study found that 94.5\% experienced Chaupadi (Menstrual Shed) during their menarche which is supported by a study that states that Chaupadi practice, was in existence in the mid- and far-western regions of Nepal [5]. Phenomenological study from this study too supported that Chaupadi was still common. But this kind of trend is decreasing comparing to past studies. Dissimilarities were found where some people had desire to continue while some were against this. Chhaupadi had led to bad consequences on overall health of women causing various infections, ill health, and even death. Hence, it was found that various mothers groups were advocating for elimination of Chaupadi from their locality. The Nepal Supreme Court banned Chaupadi in 2005 [16] but government regulation does not reach remote western regions [6]. According to a UN report in 2011, within the district of Accham, 95\% of women were practicing Chaupadi[17].Girls practicing Chaupadi will stop attending school every month during this time of personal isolation, therefore sustaining the inequality in education and the stigma surrounding periods. This is due in part to poor access to and knowledge about products such as sanitary pads. There is a general lack of education on menstrual hygiene in Nepal, which is a direct result of persistent traditional beliefs and practices [18]. 
S.B. Parajuli et al. / BIBECHANA 16 (2019) 228-235: RCOST p.234 (Online Publication: Dec., 2018)

Families believe that misfortune will be brought on them by the gods if a menstruating woman is allowed in the home or any religious places [19]. In the eyes of many in remote villages of western Nepal, ignoring Chaupadi would bring ruin to everyone. Beliefs on Chaupadipersist even when rape and underage pregnancy are the tragic consequence [20]. Women died from asphyxiation or burned to death when they built fires in the cramped sheds to shield from the Himalayan winter [20]. A legislation passed by the Parliament effective from August 2018 stated, "A woman during her menstruation or post-natal state should not be kept in Chaupadi or treated with any kind of similar discrimination or untouchable and inhuman behaviour". Anyone who forces a woman to follow Chaupadi may face a three month jail sentence or a 3000 Nepalese rupee fine or both. The law was effective from August 2018 [21, 22]. The females suffer from physiological, mental and emotional stress. The conditions in the Goth are deplorable. The mental, physical and reproductive wellbeing of the females are compromised as they suffer due to poor hygiene, poor nutrition, heavy workload and lack of security. Their basic human rights are being denied to them [21].

\section{Conclusion}

The know-do gap on menstruation was evident. Despite increasing awareness, people are still following traditional Chaupadi culture.

\section{Recommendations}

The authors would like recommend meta-analysis and systematic review of menstrual awareness and practices related research conducted in different parts of Nepal that could bring the concluding finding. In new federal health system of Nepal where local bodies are responsible for developing their health policy, the need of actual awareness and practices on menstruation needs to be explored and act on its solution.

\section{Limitation of the Study}

We could not asses the different menstrual health problems and its association with knowledge and practice score. The inclusion of more sample would be better to generalization of the findings.

\section{Acknowledgement}

Authors would like to acknowledge all participants for their support, time and participation without them this study would not have been possible. The author would like to thank local leaders and health care workers for their coordination and support.

\section{Conflict of Interest}

Authors declared no conflict of interest.

\section{Financial Disclosure}

Authors declared no financial support or grant for this research work. 


\section{References}

[1] A. Pradhan A, Is menstrual hygiene and management an issue for adolescent school girls? Water Aid, 2009.

[2] Devi K Drakshayani, Ramaiah P . Venkata, A study on menstrual hygiene among rural adolescent girls, Indian journal of medical sciences 48(6) (1994)139-43. PMID: 7927585.

[3] D. Sapkota, D. Sharma, S.S. Budhathoki, V.K. Khanal, H.P. Pokharel, Knowledge and practices regarding menstruation among school going adolescents of rural Nepal, Journal of Kathmandu Medical College 2(5) (2013) 122-128.

[4] D. Deo, D. C. Ghataraj, Perceptions and practices regarding menstruation: a comparative study in urban and rural adolescent girls, Indian Journal of Community Medicine 30 (2005) 33-4.

[5] S. Kadariya, A. R. Aro, Chhaupadi practice in Nepal-analysis of ethical aspects, Medicolegal and Bioethics5 (2015) 53-8.

[6] H. Robinson, Chaupadi: The affliction of menses in Nepal. International journal of women's dermatology 1(4) (2015) 193-4. PMID: 28491991.

[7] P. Adhikari, B. Kadel, S.I. Dhungel, A. Mandal, Knowledge and practice regarding menstrual hygiene in rural adolescent girls of Nepal Kathmandu University medical journal 5(19) (2007) 382-386

[8] A. Dasgupta, M. Sarkar, Menstrual hygiene: how hygienic is the adolescent girl?. Indian Journal of Community Medicine 33(2) (2008) 77-80.

[9] M.N. Tundia, D.V. Thakrar, A study of the menstrual problems and hygiene practices among adolescents in secondary school, Thiruvanthepuram Indian Journal of Pediatrics 1 (2012)79.

[10] M.L. Marván, P. Trujillo, Menstrual Socialization, Beliefs, and Attitudes Concerning Menstruation in Rural and Urban Mexican Women, Health care for women international, 31(1) (2009) 53-67.

[11] P. Parajuli, N. Paudel, S. Shresth, Knowledge and practices regarding menstrual hygiene among adolescent girls of rural Nepal 5(1) (2017) 5.

[12] A. Kapoor, S. Khari, Knowledge, Attitude and Socio-cultural Beliefs of Adolescent Girls towards Menstruation 36(1) (2016) 8.

[13] S. A. Shaik, R.T. Hashim , S.F. Alsukait, G.M. Abdulkader, H.F. AlSudairy, L.M. AlShaman, et al. Assessment of age at menarche and its relation with body mass index in school girls of Riyadh, Saudi Arabia 7(2) (2015) 8.

[14] R.N. Yadav, S. Joshi, R. Poudel, P. Pandeya, Knowledge, Attitude, and Practice on Menstrual Hygiene Management among School Adolescents, Journal of Nepal Health Research Council 15(3) (2018) 212-6. PMID: 29353891.

[15] M.N. Tundia, D.V. Thakrar, A study on menstrual hygiene practices and problems amongst adolescent girls in Udaipur, Rajasthan 5(8) (2018) 6.

[16] The Supreme Court of Nepal. Law Against Chhaupadi, 2005.

[17] United Nations Resident and Humanitarian Coordinator's Office, Chaupdi in the far-west, 2011. Available at: ttps://www.ohchr.org/Documents/Issues/Water/ContributionsStigma/others/field_bulletin_issue1_april_2011__chaupadi_in_far-west.pdf

[18] D.N. Bhatta, U.R. Aryal, K. Khanal, Education: the key to curb HIV and AIDS epidemic, Kathmandu University medical journal 11(42) (2013) 158-61. PMID: 24096225.

[19] C. Sauve, The red huts of Nepal. 2014, Available at: http://mindthis.ca/red-huts-nepal-isolation-duemenstruation.

[20] A. Gaelstel, The New York Times, 2013. Women in Nepal suffer monthly ostracization. Available at: http://pulitzercenter.org/reporting/nepal-achham-women-chaupadi-menstruation-ostracize-goth-traditionhindu-rape-violence-segregation.

[21] Meghna, Even Padman Cannot Save These Women From The Practice of Chhaupadi, 2018. Available at: http://www.legaldrift.com/even-padman-cannot-save-these-women-from-the-practice-of-chhaupadi/.

[22] Nepal finally criminalises 'chhaupadi, 2018. Available at: http://www.neweurope.eu/article/nepal-finallycriminalises-chhaupadi/. 